\title{
Second-line Erlotinib or Intermittent Erlotinib plus Docetaxel in Male Ex-smokers with Squamous NSCLC: The TALISMAN Randomized Trial
}

\author{
CESARE GRIDELLI ${ }^{1}$, ANTONIO CHELLA ${ }^{2}$, GIUSEPPE VALMADRE ${ }^{3}$, GIACOMO ALLEGRINI ${ }^{4}$, \\ MATTEO BRIGHENTI ${ }^{5}$, PAOLO BIDOLI ${ }^{6}$, ANTONIO ROSSI ${ }^{1}$, PAOLO MAIONE ${ }^{1}$, \\ MARIA RITA MIGLIORINO ${ }^{7}$, SERENA RICCIARDI $^{7}$ and FILIPPO DE MARINIS ${ }^{8}$ \\ ${ }^{1}$ Division of Medical Oncology, S.G. Moscati Hospital, Avellino, Italy; \\ ${ }^{2}$ University Hospital, Pisa, Italy; \\ ${ }^{3}$ ASST Valtellina e Alto Lario, Sondrio, Italy; \\ ${ }^{4}$ Az-USL 5 Pisa, Pisa, Italy; \\ ${ }^{5}$ Cremona Hospital, Cremona, Italy; \\ ${ }^{6}$ San Gerardo Hospital, Monza, Italy; \\ ${ }^{7}$ San Camillo Hospital, Roma, Italy; \\ ${ }^{8}$ Thoracic Oncology Division, European Institute of Oncology (IEO), Milan, Italy
}

\begin{abstract}
Background/Aim: The TArceva and docetaxeL In former-Smokers MAle patients with recurrent non-small cell lung cancer (TALISMAN) phase II, open-label randomized trial evaluates the combination of erlotinib with docetaxel in the second-line therapy of ex-smoker males with advanced squamous non-small cell lung cancer (NSCLC). Patients and Methods: Patients received erlotinib $150 \mathrm{mg} /$ day (arm $\mathrm{A} ; \mathrm{n=36}$ ) or docetaxel $75 \mathrm{mg} / \mathrm{m}^{2}$ on day 1 of each 3-week cycle and erlotinib $150 \mathrm{mg} /$ day on days 2-16 of each cycle (arm B; $n=38$ ). The primary end-point was progression-free rate (PFR) at 6 months. Results: The study was prematurely interrupted due to slow enrolment. Three (8.3\%) patients in arm $A$ and $3(8.1 \%)$ in arm $B$ remained progression-free at 6 months. Median progressionfree survival (PFS) was 2.3 months in arm $A$ and 2.8 months in arm B. Median overall survival (OS) was 5.6 and 8.9 months, respectively. Overall, $77.8 \%$ of patients in arm $A$ and $89.2 \%$ in arm $B$ experienced treatment-related adverse events (AEs). Conclusion: Results do not support further investigation of the combination of erlotinib and docetaxel in this setting.
\end{abstract}

Correspondence to: Cesare Gridelli, Division of Medical Oncology, S.G. Moscati Hospital, Contrada Amoretta 3- 83100 Avellino, Italy. Tel: +39 0825-203573, Fax +39 0825203556, e-mail: cgridelli@libero.it

Key Words: Combination therapy, docetaxel, erlotinib, males, NSCLC, second-line treatment, smokers.
Lung cancer remains the most common cancer worldwide and currently represents the leading cause of cancer-related deaths in Western countries (1). Non-small cell lung cancer (NSCLC) accounts for the wide majority of all lung cancers, with a frequency ranging from $80 \%$ to $85 \%$ (2).

Chemotherapy, either platinum-based or non-platinumbased, is the standard first-line treatment for patients with advanced NSCLC (3-6). Despite the fact that first-line chemotherapy is associated with clinical benefit, virtually all patients experience disease progression; of these, $40-50 \%$ receive a second-line treatment (7). At present, the European Medicinal Agency (EMA) has approved for the second-line treatment of NSCLC: docetaxel, pemetrexed, only in nonsquamous NSCLC, erlotinib, an epidermal growth factor receptor tyrosine kinase inhibitor (EGFR-TKI), and nivolumab, an immunotherapeutic directed against the programmed-death 1 (PD-1). In adenocarcinoma histology, EMA approved also the combination of docetaxel and nintedanib, a vascular endothelial growth factor receptor (VEGFR), while the combination of docetaxel and ramucirumab, a monoclonal antibody directed against VEGFR, is approved in all histologies.

In particular, erlotinib has shown activity as monotherapy of NSCLC (8). Another option to improve outcome may be to combine erlotinib and chemotherapy. Although front-line phase III studies on this strategy in advanced NSCLC patients were negative $(9,10)$, the sequential administration of chemotherapy and erlotinib may overcome the possible negative interaction that could arise when they are administered simultaneously (9-15). Of note, the promising 
results observed in a phase I/II study that evaluated the therapeutic sequence of docetaxel followed by erlotinib justify a further exploration of this scheme in another phase II study (13).

The TArceva and docetaxeL In former-Smokers MAle patients with recurrent non-small cell lung cancer (TALISMAN) phase II randomized trial evaluates the combination of docetaxel and erlotinib according to an intermittent treatment scheme, in the second-line therapy of male ex-smoker NSCLC patients (16). This subset of patients is numerically relevant with a worse prognosis compared to others and few available therapies of limited efficacy.

\section{Patients and Methods}

Setting. The TALISMAN trial was conducted in 16 Italian Oncology Centers located all over the country. The study started in November 2010 and the last enrolment was in December 2012 (study end: July 2014). The trial was conducted according to the Helsinki Declaration and the study protocol was approved by the local Ethics Committees as appropriate. All patients signed an informed consent before inclusion.

Patients. Male patients $\geq 18$ years with locally advanced (stage IIIb) or metastatic (Stage IV) or recurrent squamous NSCLC and $\geq 1$ bidimensionally measurable lesion according to RECIST 1.1 criteria were eligible. All patients were ex-smokers (i.e. patients who smoked at least 100 cigarettes in their life and who quit smoking before the enrolment in the study) and had progressed after firstline platinum-based chemotherapy with all treatment-related toxicities resolved. Other inclusion criteria were as follows: Eastern Cooperative Oncology Group Performance Status (ECOG PS) 0-1; life expectancy $\geq 12$ weeks; and adequate hematological, liver and renal function. Patients with other concomitant unstable systemic disease, history of other cancers or known hypersensitivity to erlotinib, docetaxel or any of the excipients were excluded.

Design and interventions. This was an open-label, randomized, twoarm, multicenter, phase II study. Randomization was performed centrally in a 1:1 ratio, according to a computer-generated list, and in an open-label fashion. Treatment arm A received erlotinib $150 \mathrm{mg} /$ day as monotherapy, up to progression of disease (PD), death or unacceptable toxicity. Treatment arm B received docetaxel $75 \mathrm{mg} / \mathrm{m}^{2}$ on Day 1 of each 3-week cycle and erlotinib $150 \mathrm{mg}$ /day from Day 2 to Day 16 of each 3-week cycle; the combination was administered for 4 cycles in absence of PD, death or unacceptable toxicity, which were followed by the administration of erlotinib $150 \mathrm{mg} /$ day as monotherapy up to PD, death or unacceptable toxicity.

Dose reductions and/or interruptions were allowed in case of adverse events (AEs) according to pre-defined protocols. Full supportive care was administered according to the standard practice of each center. Any concomitant medication was permitted at investigator's discretion with the exception of other oncological treatments. Patients were evaluated every 21 days for the first two months and every 30 days thereafter.

End points. The primary objective of this study was to evaluate the efficacy of erlotinib and erlotinib combined with docetaxel by using progression-free rate ((PFR); defined as the proportion of patients alive and progression-free at 6 months after randomization) at 6 months as primary end point. The secondary end points of this study were as follows: progression-free survival ((PFS); defined as the interval between the date of randomization and the first documentation of PD or death from any cause); overall survival ((OS); defined as the interval between the date of randomization and death from any cause); overall response rate ((ORR); defined as the sum of complete response (CR) and partial response (PR) rates and considering the best response achieved); disease control rate ((DCR); defined as the sum of CR, PR and stable disease (SD) rates) at 6 months, as well as duration of response. Safety considerations were also performed: type and grade of AEs, physical examination and measurement of laboratory assessments and vital signs.

Tumor response was evaluated according to the RECIST 1.1 criteria. Toxicity was graded according to the National Cancer Institute Common Terminology Criteria for AEs, version 3.0.

Statistical analysis. With chemotherapy, it was expected that about $25 \%$ of patients undergoing a second-line treatment would be without progression at 6 months (17). Based on this hypothesis, the following estimations were made: Arm A had to include 50 patients. This number was determined with the objective of estimating a proportion of progression-free patients equal to $25 \%$ and a corresponding $95 \%$ confidence interval (CI) with an error boundary of $\pm 12 \%$. In arm $B$, the number of patients was determined on the basis of the following assumptions: single-stage Fleming design; alpha error $=0.05$; beta error $=0.10 ; \mathrm{P} 0$ (minimum acceptable rate of patients without progression at 6 months) $=25 \%$; P1 (scheduled acceptable rate of patients without progression at 6 months) $=45 \%$. With these assumptions, the number of patients to be enrolled was equal to 46 . Increasing the number to 50 patients, a power of $92 \%$ was obtained. With 50 patients, 19 or more progression-free patients were required to define the result as positive. Overall 100 patients (50 in each arm) were to be enrolled.

All data were summarized by descriptive statistics. Evaluations were performed with an intent-to-treat (ITT) basis. Survival functions were evaluated using the Kaplan-Meier method.

\section{Results}

Patient population and disposition. Due to difficulties in enrolment, the study was prematurely interrupted with 74 patients enrolled in total; all subjects were randomized. Of the 74 enrolled patients, 36 were assigned to arm A and 38 to arm B. One patient in arm B did not receive treatment due to an AE before the first administration of study drug.

Patients' disposition is displayed in Figure 1. Five patients (14\% of treated) in arm A and 2 patients (5\% of treated) in arm B completed the study. The most common reason for ending treatment was PD with $22(61 \%)$ patients in arm A and $24(63 \%)$ patients in arm B. There were no substantial differences between the two arms in mean demographic data (Table I). Six (17\%) patients in arm A and $6(16 \%)$ in arm B underwent previous surgery for tumor treatment. All patients had received previous platinum-based first-line chemotherapy. The mean time from the last cycle was $4.9 \pm 6.7$ months in arm $\mathrm{A}$ and $4.2 \pm 4.0$ months in arm B. The mean number of total 


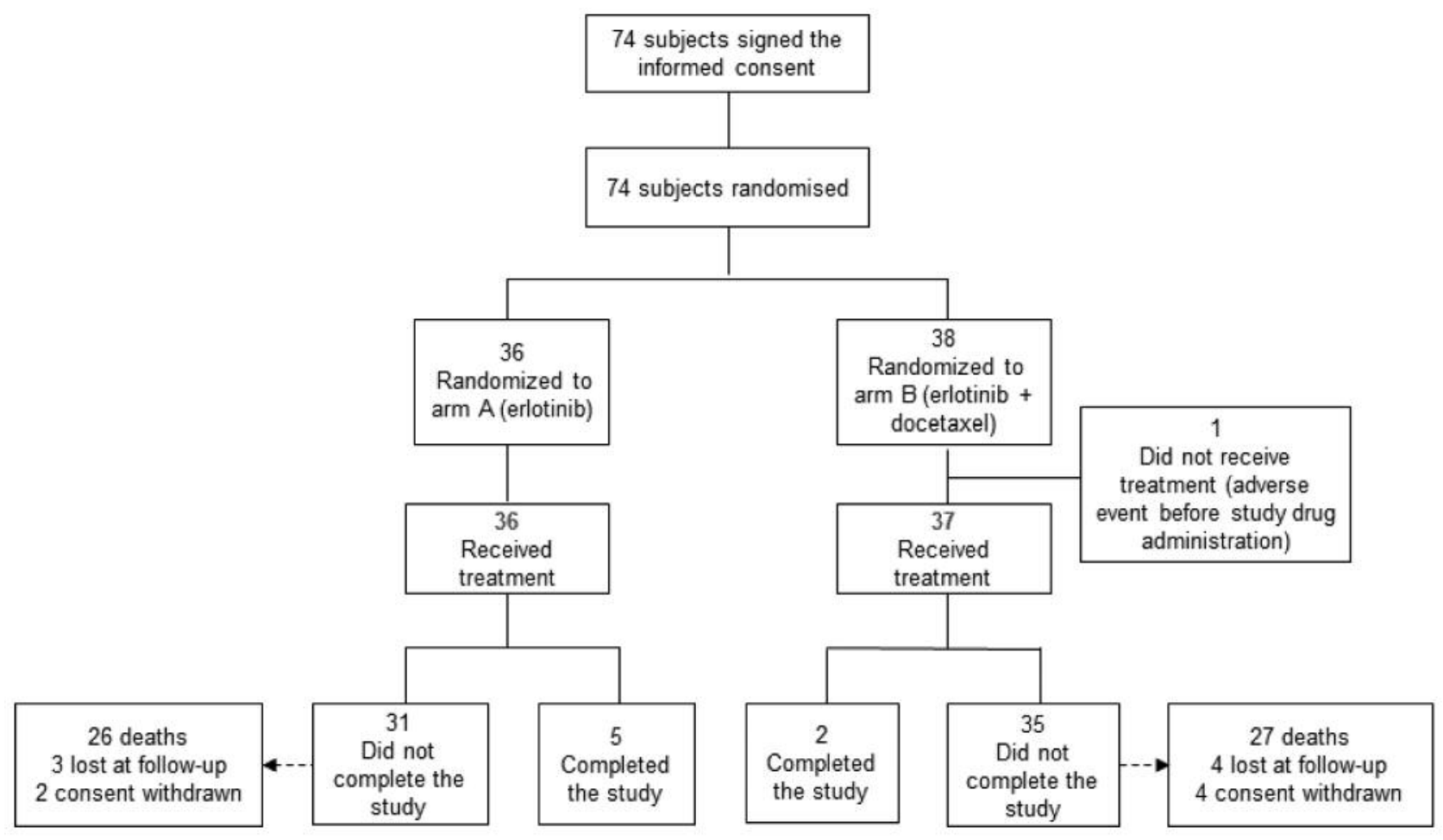

Figure 1. Patients' disposition.

cycles was $4.9 \pm 1.6$ in arm $\mathrm{A}$ and $4.2 \pm 1.3$ in arm B. More patients in arm B (46\%) than in arm A $(28 \%)$ had PD as best response to first-line treatment.

Efficacy end-points. In total, $3(8.3 \% ; 95 \% \mathrm{CI}=0.0-17.4 \%)$ patients in arm A and $3(8.1 \% ; 95 \% \mathrm{CI}=0.0-16.9 \%)$ in arm $\mathrm{B}$ were progression-free at 6 months. Of the $33(91.7 \%)$ nonprogression-free patients in arm A, 25 (75.8\%) had PD, 4 $(12.2 \%)$ did not have tumor evaluation at 6 months (all were withdrawn due to unacceptable toxicity), $2(6.1 \%)$ withdrew consent and $2(6.1 \%)$ died. Of the 34 (91.9\%) nonprogression-free patients in arm B, $24(70.6 \%)$ had PD, 4 $(11.8 \%)$ did not have tumor evaluation at 6 months (3 patients were withdrawn due to unacceptable toxicity and 1 was withdrawn due to investigator's decision), 4 (11.8\%) withdrew consent and $2(5.9 \%)$ died. Disease re-assessment at 6 months was performed in $5(13.9 \%)$ patients in arm A and in $4(10.8 \%)$ in arm B.

Median PFS was 2.3 months (95\% CI=2.1-4.1) in arm A and 2.8 months $(95 \% \mathrm{CI}=2.3-4.0)$ in arm B (Figure 2A). Median OS was 5.6 months $(95 \% \mathrm{CI}=3.5-8.6)$ in arm $\mathrm{A}$ and 8.9 months $(95 \% \mathrm{CI}=6.1-10.4$ in arm B (Figure $2 \mathrm{~B})$.

One $(2.8 \% ; 95 \% \mathrm{CI}=0.0-8.15 \%)$ patient in arm $\mathrm{A}$ and 3 $(8.1 \% ; 95 \% \mathrm{CI}=0.0-16.9 \%)$ in arm B were responders, with $\mathrm{PR}$ as best response ( 7 and 5 patients were not evaluable for
Table I. Baseline characteristics.

\begin{tabular}{lcc}
\hline & $\begin{array}{c}\text { Arm A } \\
(\mathrm{N}=36)\end{array}$ & $\begin{array}{c}\text { Arm B } \\
(\mathrm{N}=37)\end{array}$ \\
\hline Age (years), mean \pm StD & $68.4 \pm 8.3$ & $65.9 \pm 8.1$ \\
Weight $(\mathrm{kg})$, mean $\pm \mathrm{StD}$ & $78.4 \pm 15.4$ & $74.2 \pm 12.8$ \\
Height $(\mathrm{cm})$, mean $\pm \mathrm{StD}$ & $169.0 \pm 7.9$ & $169.6 \pm 6.9$ \\
$\mathrm{SBP}(\mathrm{mmHg})$, mean $\pm \mathrm{StD}$ & $127.0 \pm 12.8$ & $124.8 \pm 10.9$ \\
DBP $(\mathrm{mmHg})$, mean $\pm \mathrm{StD}$ & $80.2 \pm 5.8$ & $77.3 \pm 5.0$ \\
Heart rate $(\mathrm{bpm})$, mean \pm StD & $82.4 \pm 8.9$ & $77.4 \pm 7.5$ \\
Duration of smoking $($ years $)$, mean $\pm \mathrm{StD}$ & $39.7 \pm 13.1$ & $38.3 \pm 11.0$ \\
Number of smoked cigarettes/day, mean $\pm \mathrm{StD}$ & $26.6 \pm 14.4$ & $25.5 \pm 11.3$ \\
ECOG PS, N $(\%)$ & & \\
0 & $11(30.6 \%)$ & $14(37.8 \%)$ \\
1 & $24(66.7 \%)$ & $23(62.2 \%)$ \\
2 & $1(2.8 \%)$ & $0(0.0 \%)$ \\
\hline
\end{tabular}

$\mathrm{StD}$, Standard deviation.

response, respectively). Stable disease was reported in 14 (38.9\%) and $11(29.7 \%)$ patients, respectively, for an overall disease control rate of $41.7 \%$ and $37.8 \%$, respectively. The median duration of response was not evaluable in arm A (only one responder); it was, however, 8.69 months in arm B $(95 \%$ CI $=1.87-10.8)$. 


\section{A}

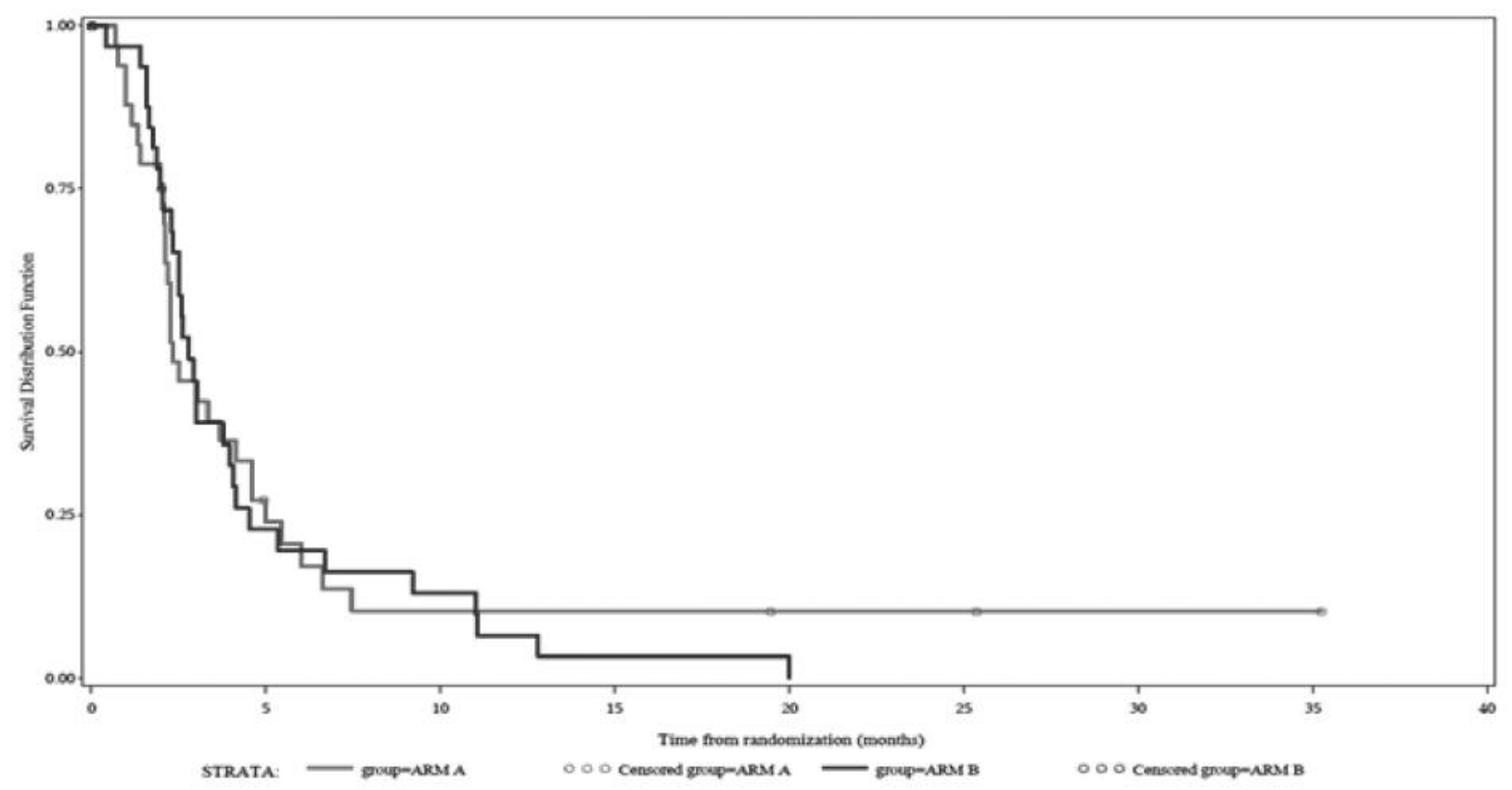

\begin{tabular}{lcccccccc}
\hline & Month5 & Month 10 & Month15 & Month20 & Month25 & Month30 & Month 35 & Month40 \\
\hline Arm A & 8 & 3 & 3 & 2 & 1 & 1 & 1 & 0 \\
\hline Arm B & 7 & 3 & 1 & 0 & 0 & 0 & 0 & 0 \\
\hline
\end{tabular}

B

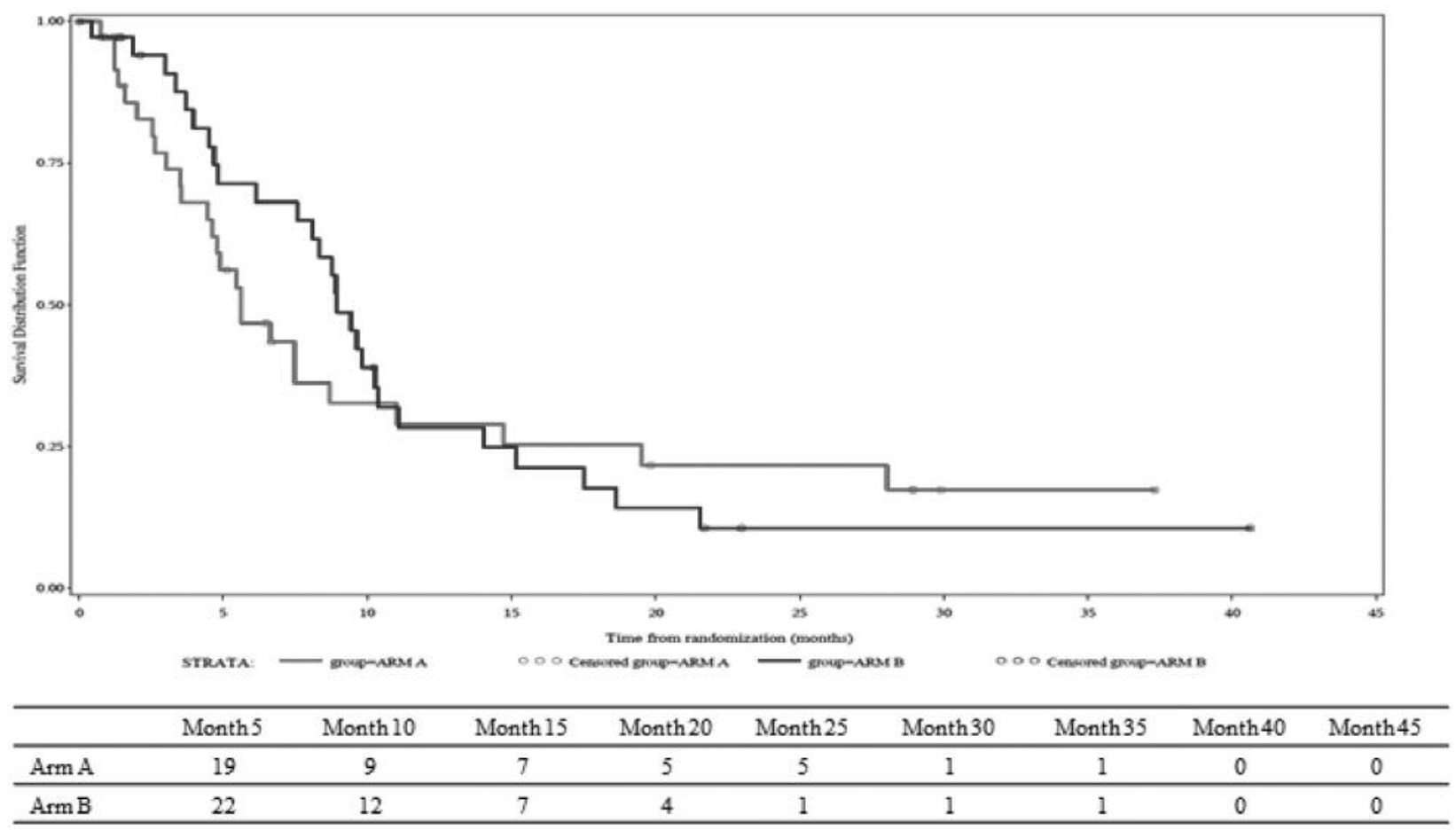

Figure 2. Kaplan-Meier analysis of progression-free survival (Panel A) and overall survival (Panel B). 
Safety evaluations. Apart from one patient in arm A, all patients in both arms experienced at least one AE. The rate of patients with treatment-related AEs was higher in arm B (33 patients, $89.2 \%$ ) than in arm A (28 patients, $77.8 \%$ ). More patients in arm A (28 patients, $77.9 \%)$ than in arm B (15 patients, $40.5 \%$ ) had AEs related only to erlotinib. Treatment-emergent adverse events (TEAEs) related only to docetaxel were reported in 19 patients $(51.4 \%)$ in arm B.

Fatal AEs occurred in 7 patients $(19.4 \%$ ) in arm A (two cases of general health deterioration, two cases of gastrointestinal hemorrhage/ulcer, cough and dyspnea, acute respiratory failure and cachexia). Three patients $(8.1 \%)$ had fatal AEs in arm B (pneumonia, neutropenia and unknown). The rate of patients with serious AEs was higher in arm A (15 patients, $41.7 \%)$ than in arm B (10 patients, $27.0 \%)$. Grade $\geq 3$ AEs were reported in similar rates in the two groups $(66.7 \%$ of patients in arm A and $62.2 \%$ of patients in arm B). Seven patients (19.4\%) in arm A and $13(35.1 \%)$ in arm B discontinued the study due to TEAEs.

Table II summarizes tolerability data. The most common AEs were: rash (44.4\% in arm $\mathrm{A}$ and $32.4 \%$ in arm B), diarrhea (25.0\% and $37.8 \%)$ and asthenia (16.7\% and $21.6 \%)$.

No clinically-relevant alterations of laboratory parameters or vital signs were reported.

\section{Discussion}

The sequential administration of erlotinib and chemotherapy represents a potentially-suitable treatment strategy for therapy of advanced NSCLC. Despite the fact that initial studies led to disappointing results $(9,10)$ when this chemotherapy and erlotinib were given concomitantly, more recent evidence seems to suggests some effects of the sequential approach (14, $15)$. More in detail, in the second-line setting, an OS benefit was observed with erlotinib $150 \mathrm{mg}$ during 15 days intercalated with four 21-day cycles of docetaxel or pemetrexed, as compared with erlotinib $150 \mathrm{mg}$ alone (although this effect was primarily observed in patients with non-squamous histology) (14). The increased efficacy of combining these drugs is thought to be mediated by mechanisms not only related to the genetic signature of the tumor cells; for instance, docetaxel and EGFR inhibition were found to synergistically increase the antiproliferative and cytotoxic effect of the individual drugs in experimental models $(14,18)$.

The results of the present study, unfortunately, do not lend immediate support to the above-mentioned findings. In fact, the results of the primary efficacy end-point showed that the PFR at 6 months was markedly lower than expected with comparable rates in the two arms $(8.3 \%$ and $8.1 \%$ for the erlotinib only and combination arm, respectively). Similarly, the median PFS and the ORR/DCR was comparable in the two groups, whereas the median OS was longer in the erlotinib + docetaxel arm than in the erlotinib monotherapy
Table II. Adverse events in the study groups. Data in each column for arms $A$ and $B$ show number of patients (\%) (number of events).

\begin{tabular}{lcc}
\hline Adverse events & $\begin{array}{c}\text { Arm A } \\
(\mathrm{N}=36)\end{array}$ & $\begin{array}{c}\text { Arm B } \\
(\mathrm{N}=37)\end{array}$ \\
\hline Rash & $16(44.4 \%)(26)$ & $12(32.4 \%)(22)$ \\
Diarrhea & $9(25.0 \%)(14)$ & $14(37.8 \%)(20)$ \\
Asthenia & $6(16.7 \%)(6)$ & $8(21.6 \%)(9)$ \\
Neutropenia & $0(0.0 \%)(0)$ & $11(29.7 \%)(13)$ \\
Mucosal inflammation & $1(2.8 \%)(1)$ & $6(16.2 \%)(10)$ \\
Nausea & $2(5.6 \%)(2)$ & $3(8.1 \%)(3)$ \\
Febrile neutropenia & $0(0.0 \%)(0)$ & $5(13.5 \%)(5)$ \\
Decreased appetite & $2(5.6 \%)(2)$ & $3(8.1 \%)(4)$ \\
Vomiting & $0(0.0 \%)(0)$ & $4(10.8 \%)(4)$ \\
Erythema & $3(8.3 \%)(3)$ & $1(2.7 \%)(1)$ \\
Anemia & $1(2.8 \%)(1)$ & $2(5.4 \%)(2)$ \\
Pyrexia & $0(0.0 \%)(0)$ & $3(8.1 \%)(3)$ \\
Anaphylactic reaction & $0(0.0 \%)(0)$ & $3(8.1 \%)(3)$ \\
Hypertransaminasemia & $2(5.6 \%)(2)$ & $1(2.7 \%)(1)$ \\
Folliculitis & $2(5.6 \%)(2)$ & $1(2.7 \%)(1)$ \\
Leukopenia & $0(0.0 \%)(0)$ & $2(5.4 \%)(3)$ \\
Coordination abnormal & $0(0.0 \%)(0)$ & $2(5.4 \%)(2)$ \\
Neuropathy peripheral & $0(0.0 \%)(0)$ & $2(5.4 \%)(2)$ \\
Dry skin & $2(5.6 \%)(2)$ & $0(0.0 \%)(0)$ \\
Urticaria & $0(0.0 \%)(0)$ & $2(5.4 \%)(2)$ \\
\hline
\end{tabular}

arm. Interestingly, the survival rate at 1 and 2 year(s) was remarkably high, thus potentially suggesting the existence of a population of long-responding patients who need to be identified in dedicated studies. No unexpected safety concerns were reported.

It must be observed that the study was prematurely interrupted with 74 randomized patients in total, instead of the 100 scheduled patients due to slow accrual. A number of factors can have accounted for this suboptimal accrual. One of these factors can be the introduction in the therapeutic scenario of novel targeted therapies directed against mutated $E G F R$, which probably raised some skepticism in clinicians in treating patients with erlotinib without a molecular target and move to different therapies other than those evaluated in this trial (19-21).

In conclusion, this study, even if prematurely interrupted, showed that the intermittent docetaxel plus erlotinib combination strategy should not be furtherly investigated in the treatment of ex-smoker males with advanced squamous NSCLC.

\section{Acknowledgements}

This study was sponsored by Roche. The Authors declare no conflicts of interest directly relevant to this study. Editorial assistance for the preparation of this manuscript was provided by Luca Giacomelli, PhD, on behalf of Content Ed Net; this assistance was funded by Roche. 


\section{References}

1 Ferlay J, Soerjomataram I, Dikshit R, Eser S, Mathers C, Rebelo M, Parkin DM, Forman D and Bray F: Cancer incidence and mortality worldwide: Sources, methods and major patterns in GLOBOCAN 2012. Int J Cancer 136: E359-386, 2015.

2 Siegel R, Ma J, Zou Z and Jemal A: Cancer statistics, 2014. CA Cancer J Clin 64: 9-29, 2014.

3 Gridelli C, Rossi A, Carbone DP, Guarize J, Karachaliou N, Mok T, Petrella F, Spaggiari L and Rosell R: Non-small cell lung cancer. Nat Rev Prim Dis 1: 1-16, 2015.

4 Joshi M, Liu X and Belani CP: Taxanes, past, present, and future impact on non-small cell lung cancer. Anticancer Drugs 25: 571$583,2014$.

5 Caffo O, Dipasquale M, Murgia V, Veccia A and Galligioni E: An evaluation of the pharmacokinetics and clinical use of vinorelbine for NSCLC treatment. Expert Opin Drug Metab Toxicol 9: 1037-1351, 2013.

6 Brown T, Pilkington G, Bagust A, Boland A, Oyee J, TudurSmith C, Blundell M, Lai M, Martin Saborido C, Greenhalgh J, Dundar $\mathrm{Y}$ and Dickson R: Clinical effectiveness and costeffectiveness of first-line chemotherapy for adult patients with locally advanced or metastatic non-small cell lung cancer: A systematic review and economic evaluation. Health Technol Assess 17: 1-278, 2013.

7 de Marinis F and Ricciardi S: Second-line treatment options in advanced non-small cell lung cancer. Eur J Cancer 47(Suppl 3): S258-271, 2011.

8 Shepherd FA, Rodrigues Pereira J, Ciuleanu T, Tan EH, Hirsh V, Thongprasert S, Campos D, Maoleekoonpiroj S, Smylie M, Martins R, van Kooten M, Dediu M, Findlay B, Tu D, Johnston D, Bezjak A, Clark G, Santabárbara P and Seymour L; National Cancer Institute of Canada Clinical Trials Group: Erlotinib in previously treated non-small cell lung cancer. N Engl J Med 353: 123-132, 2005.

9 Herbst RS, Prager D, Hermann R, Fehrenbacher L, Johnson BE, Sandler A, Kris MG, Tran HT, Klein P, Li X, Ramies D, Johnson DH and Miller VA; TRIBUTE Investigator Group: TRIBUTE: A phase III trial of erlotinib hydrochloride (OSI-774) combined with carboplatin and paclitaxel chemotherapy in advanced nonsmall-cell lung cancer. J Clin Oncol 23: 5892-5899, 2005.

10 Gatzemeier U, Pluzanska A, Szczesna A, Kaukel E, Roubec J, De Rosa F, Milanowski J, Karnicka-Mlodkowski H, Pesek M, Serwatowski P, Ramlau R, Janaskova T, Vansteenkiste J, Strausz J, Manikhas GM and Von Pawel J: Phase III study of erlotinib in combination with cisplatin and gemcitabine in advanced nonsmall cell lung cancer: The Tarceva Lung Cancer Investigation Trial. J Clin Oncol 25: 1545-1552, 2007.

11 Davies AM, Ho C, Lara PN Jr., Mack P, Gumerlock PH and Gandara DR: Pharmacodynamic separation of epidermal growth factor receptor tyrosine kinase inhibitors and chemotherapy in non-small-cell lung cancer. Clin Lung Cancer 7: 385-388, 2006.

12 Chiorean EG, Porter JM, Foster AE, Al Omari AS, Yoder CA, Fife KL, Strother RM, Murry DJ, Yu M, Jones DR and Sweeney CJ: A phase I and pharmacokinetic trial of erlotinib in combination with weekly docetaxel in patients with taxane-naive malignancies. Clin Cancer Res 14: 1131-1137, 2008.
13 Sangha R, Davies AM, Lara PN Jr., Mack PC, Beckett LA, Hesketh PJ, Lau D, Li T, Perkins $\mathrm{N}$ and Gandara DR: Intercalated erlotinib-docetaxel dosing schedules designed to achieve pharmacodynamic separation: Results of a phase I/II trial. J Thorac Oncol 6: 2112-2129, 2011.

14 Aerts JG, Codrington H, Lankheet NA, Burgers S, Biesma B, Dingemans AM, Vincent AD, Dalesio O, Groen HJ and Smit EF; NVALT Study Group: A randomized phase II study comparing erlotinib versus erlotinib with alternating chemotherapy in relapsed non-small-cell lung cancer patients: The NVALT-10 study. Ann Oncol 24: 2860-2865, 2013.

$15 \mathrm{Wu}$ YL, Lee JS, Thongprasert S, Yu CJ, Zhang L, Ladrera G, Srimuninnimit V, Sriuranpong V, Sandoval-Tan J, Zhu Y, Liao M, Zhou C, Pan H, Lee V, Chen YM, Sun Y, Margono B, Fuerte F, Chang GC, Seetalarom K, Wang J, Cheng A, Syahruddin E, Qian X, Ho J, Kurnianda J, Liu HE, Jin K, Truman M, Bara I and Mok T: Intercalated combination of chemotherapy and erlotinib for patients with advanced stage non-small cell lung cancer (FASTACT-2): A randomised, double-blind trial. Lancet Oncol 14: 777-786, 2013.

16 Gridelli C, Rossi A, Venturino P and de Marinis F: Treatment, rationale, and study design of TALISMAN study: A randomized phase II open-label study of second-line erlotinib versus intermittent erlotinib dosing with docetaxel in the treatment of former smoker men affected by recurrent squamous non small cell lung cancer. Clin Lung Cancer 12: 70-73, 2011.

17 Hanna N, Shepherd FA, Fossella FV, Pereira JR, De Marinis F, von Pawel J, Gatzemeier U, Tsao TC, Pless M, Muller T, Lim HL, Desch C, Szondy K, Gervais R, Shaharyar, Manegold C, Paul S, Paoletti P, Einhorn L and Bunn PA Jr.: Randomized phase III trial of pemetrexed versus docetaxel in patients with non-small-cell lung cancer previously treated with chemotherapy. J Clin Oncol 22: 1589-1597, 2004.

18 Mahaffey CM, Davies AM and Lara PN Jr.: Schedule-dependent apoptosis in K-ras mutant non-small-cell lung cancer cell lines treated with docetaxel and erlotinib: Rationale for pharmacodynamic separation. Clin Lung Cancer 8: 548-553, 2007.

19 Stinchcombe TE: Novel agents in development for advanced non-small cell lung cancer. Ther Adv Med Oncol 6: 240-253, 2014.

20 Melosky B: Review of EGFR TKIs in metastatic NSCLC, including ongoing trials. Front Oncol 4: 244, 2014.

21 Gridelli C, de Marinis F, Cappuzzo F, Di Maio M, Hirsch FR, Mok T, Morgillo F, Rosell R, Spigel DR, Yang JC and Ciardiello F: Treatment of advanced non-small-cell lung cancer with epidermal growth factor receptor (EGFR) mutation or ALK gene rearrangement: Results of an international expert panel meeting of the Italian Association of Thoracic Oncology. Clin Lung Cancer 15: 173-181, 2014. 